\title{
THE EFFICIENCY INCREASE IN A TWO-STAGE TRANSPORT SYSTEM
}

\author{
Burinskiene, A. \\ Vilnius Gediminas Technical University, Faculty of Business Management, \\ Sauletekio al. 11, Vilnius LT-10221, Lithuania \\ E-Mail: aurelija.burinskiene@vgtu.lt
}

\begin{abstract}
In this study, the author investigates a two-stage transport system, which consists of several warehouses and demand points grouped into clusters. The study aims to identify the combination of shipping and delivery strategies, which implementation in two-stage transport system increase efficiency. To achieve this objective, the author models the costs associated with the application of those strategies in different transport solutions, proposes a framework useful for efficiency evaluation and its practical application. During a case study, the author investigates those transport solutions and specifies the most economically attractive ones allowing to achieve costs reduction for products supply to each cluster. According to the case study analysis, approximately $47 \%$ of costs could be minimised in the transport system by applying the transportation solution, which includes the combination of store order shipping and direct store delivery strategies. The scientific novelty of this research is the application of the proposed framework for efficiency examination in the two-stage transport system.

(Received in August 2020, accepted in November 2020. This paper was with the author 1 month for 2 revisions.)
\end{abstract}

Key Words: Transport System, Two-Stage, Shipping Strategy, Delivery Strategy, Costs Metrics

\section{INTRODUCTION}

The transport system includes demand flows and is treated as a network which consists of four stages (suppliers, central depot, regional warehouse or transit point and customers - demand points) [1] with selected shipping and delivery strategies. The choice of these strategies is always linked with long-term economic effect. For such selection, the suggestion of framework, which could be a helpful tool in decision making, is actual.

Transport systems are quite complex, and as the objects of research still receive the attention of researchers. Authors investigate various strategies under different problem families, but the combination of these strategies is rarely incorporated into studies.

The study seeks to identify the combination of shipping and delivery strategies that increase efficiency in the two-stage transport system. To reach this, the author develops the framework allowing to model costs and evaluate efficiency in the two-stage distribution system. The results are precious for experts interested in transport system efficiency. The originality of the research is the selection of outbound strategies and their combined application for efficiency improvement in the two-stage transport system. The author suggests the framework, which helps to minimise costs, and provides its application for the case study.

The study consists of several parts. The literature review and research methodology are presented under section 2 . In section 3, shipping and delivery strategies and their combinations are provided. The section ends with the presentation of the framework used for modelling costs in the two-stage transport system. The application of the framework for the case study is delivered in section 4 . Finally, the paper ends with the conclusions.

For this article, the author reviews a broad range of multidisciplinary studies. The review covers 20 papers presented in 14 journals. 


\section{LITERATURE REVIEW}

The transport system is quite complex, and for its efficiency increase, many strategies could be investigated. In terms of optimising costs in two-stage (or two echelons) transport system, we can distinguish several sets of problems' families: Location-Dispatching (or LocationDistribution, LDP) and Location Routing (LRP). First problem family deals with the optimisation of vehicle movement costs in the transport system and the second one - with routing, which is incorporated with the analysis of locations of the depot and intermediate DCs.

Location-Dispatching models are used by industry for customer allocation decisions, considering the costs for accessing the products by customers [2]. The problem sets the estimated expenses for delivering products to a customer from the warehouse via car parks, which are used for reloading goods from vehicle-to-vehicle inside area.

Lin and Lei formulated 2E-LRP, which is investigating the selection of the best delivery route in each stage [3]. The products could be delivered directly from the warehouse or forced to pass through transshipment DC or directly shipped to the customers. 2E-LRP is used for defining the optimal route between several warehouses. It connects the two stages and manages their interdependence. The closest formulation can be considered as a special case of 2E-LRP, in which all warehouses are already open and include no opening costs [4]. Besides, to 2E-LRP, authors applying facility location problem (2E-FLP) family search for the best place to locate a facility and using other problem families to minimise delivery costs following a vehicle and its supply schedule constraints.

Below is the presentation of main strategies and criteria, which are important for the setup of the efficient two-stage transport system and investigated in specific problem families (Table I).

Table I: Improving the efficiency in the two-stage transport system.

\begin{tabular}{|l|c|c|c|}
\hline \multirow{4}{*}{$\begin{array}{c}\text { Topics for } \\
\text { investigations }\end{array}$} & $\begin{array}{c}\text { Efficiency improvement criteria \& } \\
\text { strategies }\end{array}$ & $\begin{array}{c}\text { Problem } \\
\text { families }\end{array}$ & References \\
\hline \multirow{3}{*}{$\begin{array}{l}\text { Nature of transport } \\
\text { system }\end{array}$} & Multi-product & IRP & {$[5]$} \\
\cline { 2 - 4 } & Multi-period & IRP & {$[5],[6]$} \\
\cline { 2 - 4 } & Two-stage & FLP & {$[7]$} \\
\hline \multirow{3}{*}{$\begin{array}{l}\text { Demand side- } \\
\text { approaches }\end{array}$} & Clustering-based & VRP & {$[8]$} \\
\cline { 2 - 4 } & Vehicle usage & VRP & {$[9]$} \\
\cline { 2 - 4 } & Number of loads & TTRP & {$[10],[11]$} \\
\cline { 2 - 4 } & Volume per product & FLP & {$[7]$} \\
\hline \multirow{4}{*}{ Transportation type } & Amount per client & LRP & {$[1]$} \\
\cline { 2 - 4 } & Warehouse-to-warehouse delivery & LRP & {$[12]$} \\
\cline { 2 - 4 } & Direct delivery to customer & LRP & {$[12]$} \\
\cline { 2 - 4 } & Transshipment & IRP & {$[13]$} \\
\hline \multirow{2}{*}{ Delivery type } & Rransport with consolidation & LRP & {$[12]$} \\
\cline { 2 - 4 } & Round-trip delivery & VRP, IRP & {$[12],[14]$} \\
\hline \multirow{2}{*}{ Distance type } & One-way delivery & IRP & {$[6]$} \\
\cline { 2 - 4 } & Arch-based & LDP & {$[2],[15]$} \\
\cline { 2 - 4 } & Path-based & LDP & {$[2]$} \\
\hline
\end{tabular}

herein problem families: IRP - inventory routing problem, TTRP - truck and trailer routing problem, VRP - vehicle routing problem

Research gaps: The review of the literature shows that authors focus on various investigations in different problem families, which are important for strategic decisions and the application of outbound strategies. However, these aspects are usually not combined into mixed schemas to reach higher efficiency. So, in this paper, the author tries to connect various 
strategies into mixed schemas defined as transport solutions and investigate the opportunity for efficiency increase in the two-stage transport system.

\subsection{Research methodology}

The author analyses the two-stage retail transport system treated as multi-product and singleperiod. Four mixed schemas are constructed, which include various transportation types and delivery types. The clients are clustered, and distance among stages is assumed as the arc (or Euclidean) one [16]. The demand-side approach follows full truckloads (FTL) per cluster logic and vehicle usage (truck occupancy) investigations, where the type of order guarantees that the truck occupancy is stable for any number of loads. Two order types are stated:

1. Warehouse-to-warehouse delivery - DC order type;

2. Direct delivery to customer - Store order type.

As these variables are important for strategic decisions, the author matches the operations inside the warehouse with shipping strategies and operations outside the warehouse with delivery strategies. Three shipping and three delivery strategies are presented further on.

The author investigates costs metrics for framework development. Under costs metrics, all warehouses are treated as open, and their opening costs are not examined.

Finally, the author provides the framework for costs modelling, which application identifies the best combination of shipping and delivery strategies incorporated in different transport solutions. The costs for each transport solution are examined for each cluster which is a part of the transport system by giving guidelines on how to make the transport system more efficient.

The choice among transport solution alternatives [17] is identified per cluster. For the choice convergence method is used in such phases:

- Alternatives of transport solutions, which are not attractive economically are eliminated;

- Alternatives of transport solutions, which are left after previous elimination, are eliminated, where the reduction of total costs is the lowest.

In the next section, different combinations of shipping and delivery strategies are presented.

\section{THE DEVELOPMENT OF FRAMEWORK FOR MODELLING COSTS IN A TWO-STAGE TRANSPORT SYSTEM}

This section is dedicated to the development of the framework and its practical application for efficiency evaluation in the two-stage transport system. The section starts with the presentation of shipping and delivery strategies and their combined implementation in the two-stage transport system to increase efficiency. Later, the clustering setup for demand points is delivered in 3.2 sub-chapter. The sub-chapter 3.3 is given to costs metrics, which are important for framework development. And finally, the framework for modelling costs in the two-stage transport system is stated in the last sub-chapter of this section.

\subsection{Shipping and delivery strategies for serving demand points}

To achieve efficiency in the transport system, companies may choose different solutions. Following the characteristics of the product, positions could be separated into high-usage and low-usage goods. The high rotation items could be located at the warehouse as closer as possible to demand points, while low rotation items could be placed in a far-away location. In such a way, the transport system consists of two warehouses/distribution centres (DCs), which are in the distance. The main question to be answered what strategy to select for products delivery to demand points.

Herein, several predominant strategies could be identified: shipping and delivery ones. 
There are three main shipping strategies: shipment of homogeneous pallets (DC order), outbound of heterogeneous pallets (Store order) and shipment with the consolidation of heterogenous pallets (Consolidation).

Concerning delivery strategies, one of them is warehouse-to-warehouse (DCD) delivery strategy. Homogenous pallets are moved between warehouses and later are picked to customers. Another one is direct store delivery (DSD) when the mixed products are carried on the pallet according to Stores' orders. And transshipment is defined as the transfer of heterogeneous pallets from a primary warehouse to stores through an intermediate warehouse (Transshipment) (Table II). The combinations of these strategies affect shipping and delivery costs.

Table II: Shipping and delivery strategies in the two-stage transport system.

\begin{tabular}{|c|c|c|c|c|c|c|c|}
\hline \multirow{2}{*}{$\begin{array}{c}\text { Scenario } \\
\text { No. }\end{array}$} & \multirow{2}{*}{$\begin{array}{l}\text { Warehouse } \\
\text { location }\end{array}$} & \multicolumn{3}{|c|}{ Shipping strategy } & \multicolumn{3}{|c|}{ Delivery strategy } \\
\hline & & $\begin{array}{l}\text { DC order } \\
\text { shipping }\end{array}$ & $\begin{array}{c}\text { Store order } \\
\text { shipping }\end{array}$ & $\begin{array}{l}\text { Consolidation } \\
\text { \& shipping }\end{array}$ & DCD & DSD & $\begin{array}{l}\text { Trans- } \\
\text { shipment }\end{array}$ \\
\hline 1 & Far-away1 & $\mathrm{X}$ & & & $\mathrm{X}$ & & \\
\hline 2 & Far-away2 & & $X$ & & & & $X$ \\
\hline 3 & Far-away3 & & $\mathrm{X}$ & & & $\mathrm{X}$ & \\
\hline 4 & Near-by1 & & $\mathrm{X}$ & & & $\mathrm{X}$ & \\
\hline 5 & Near-by2 & & & $\mathrm{X}$ & & $\mathrm{X}$ & \\
\hline
\end{tabular}

For presenting the difference in order shipping type, the author provides details of operations, which are performed in warehouses [18] (Fig. 1). In particular, the shipping of DC order represents full pallets pick (Fig. 1 a) and the shipping of Store order - the carton pick (Fig. 1 b-c). Both picks result in different pallet height, which is later presented in Fig. 2.

a)

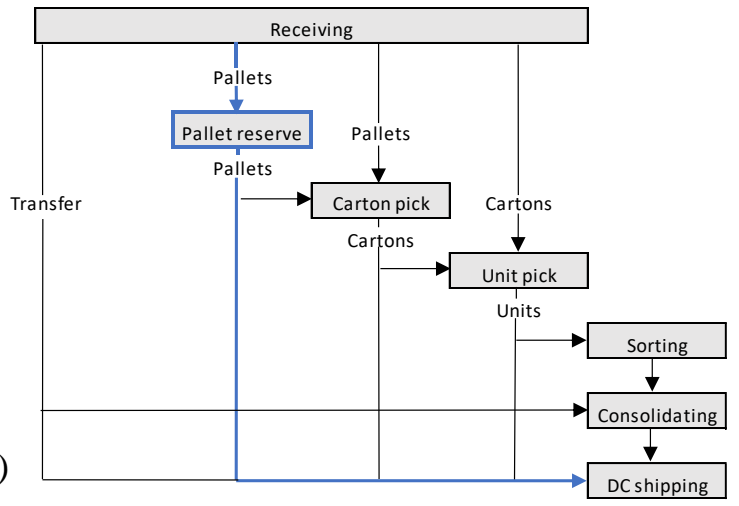

b)

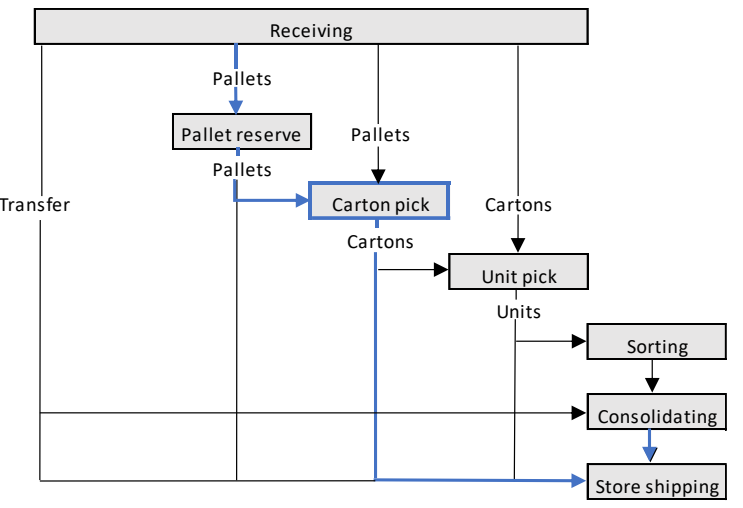

c)

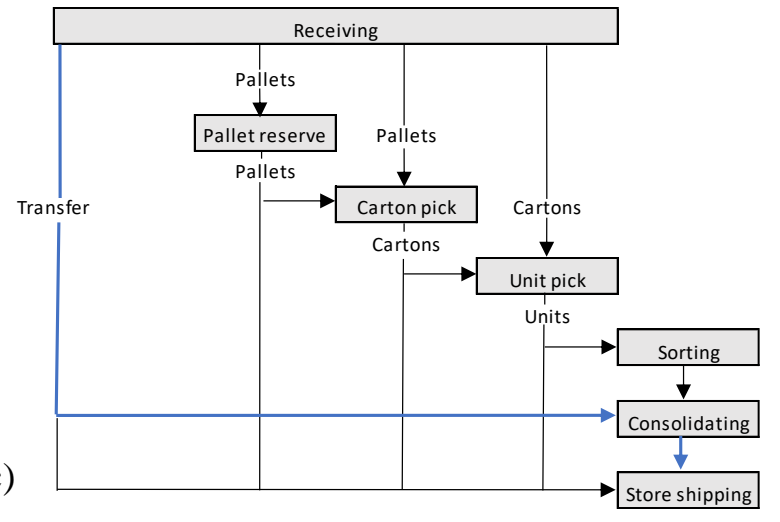

Figure 1: Different shipping strategies (constructed by the author).

In a warehouse, more labour intensive is Store order and less labour intensive in DC order preparation and shipping. The material flow in DC order shipping case is based on the following 
activities: receiving, the movement to pallet reserve, retrieval, and shipment of full pallets according to near-by DC order (Fig. 1 a). In Store order shipping case, products are received in pallets, afterwards moved to a pick area for carton pick according to the orders of demand points (Fig. 1 b), and finally loaded to the truck [19]. In transhipment case, the pallets are moved from receiving dock to shipping docks, where they are consolidated and shipped for the delivery. There are costs for pallet transfer, consolidation, and shipment (Fig. $1 \mathrm{c}$ ).

The combination of these shipping and delivery strategies represents a different effect on costs. For example, transhipment DC works with zero stock balance, and there are lower operational costs. The expenses for each delivery type are also highly dependent on pallet height [20]. In the case of DC order delivery - 1.5 meters, and, in case of Store order delivery, the height of pallet is 1.2 meters (or 1.25 times lower). As the height of the truck is 2 meters, the truck occupancy level is $60 \%$ and $75 \%$ accordingly (Fig. 2). This difference is because shipped Store order has cartons of multiple products, and DC order contains cartons of single products on the pallet.

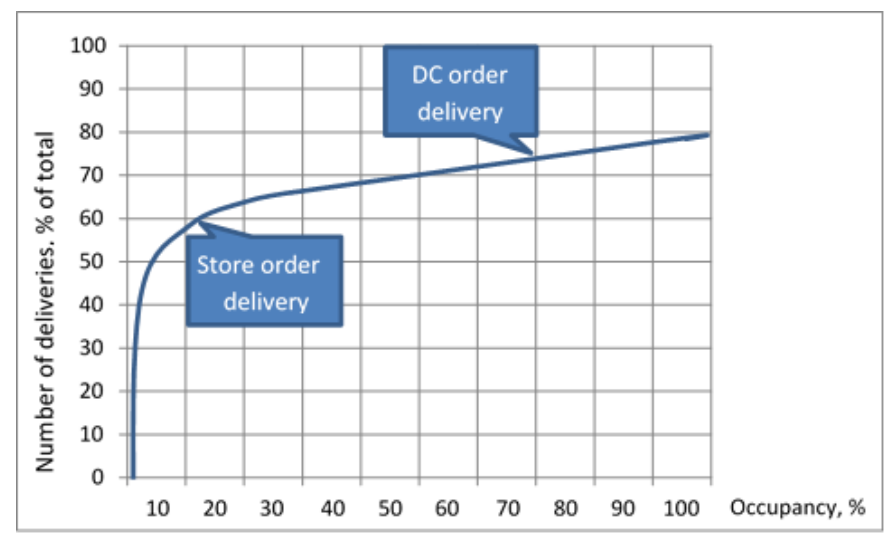

Figure 2: Delivery strategy and truck occupancy level.

To increase efficiency, the author combines shipping and delivery strategies into various transport solutions with specified delivery type, which are presented in the paper later on.

\subsection{Clustering-based two-stage transport system}

For the efficiency review, the demand points are clustered. The clustering of demand points involves several steps. For clustering, all demand points are linked with near-by cities; at the next stage, cities are grouped into sub-clusters, representing regions. At the third step, subclusters are aggregated into clusters, representing territorial units, with mid-points located not closer than the specified threshold value. After using hierarchical clustering and incorporating distance measure, the cities are linked to clusters (initialisations step). Besides, the minimum distance threshold value (termination condition) is used to identify the number of clusters (aggregative step). During the initialisation step, the cities are linked to sub-clusters, Eq. (1):

$$
P_{i}^{\prime}=\left(J_{1}, \ldots, J_{z}\right)
$$

Herein: $P^{\prime}$ - sub-cluster, $i$ - the unique number of a sub-cluster, $z$ - the number of cities.

During the aggregative step, two sub-clusters are combined into cluster $P$, Eq. (2):

$$
P_{r}=\left(P_{1}^{\prime}, P_{2}^{\prime}\right)
$$

Herein: $P$ - the cluster, $r$ - unique number of the cluster.

For Euclidean distance calculation, Latitude (Lat) and Longitude (Lon) values of two location points are included in Eq. (3) and presented in Table III. 
Table III: Distances between cities, where demand points $(n=35)$ are established.

\begin{tabular}{|c|c|c|c|c|}
\hline Cities & $\mathrm{J}_{1}\left(\mathrm{Lat}_{1}, \mathrm{Lon}_{1}\right)$ & $\mathrm{J}_{2}\left(\mathrm{Lat}_{2}, \mathrm{Lon}_{2}\right)$ & $\ldots$ & $\mathrm{J}_{n}\left(\mathrm{Lat}_{n}, \mathrm{Lon}_{n}\right)$ \\
\hline $\mathrm{J}_{1}\left(\mathrm{Lat}_{1}, \mathrm{Lon}_{1}\right)$ & 0 & & $\ldots$ & \\
\hline$\ldots$ & $\ldots$ & $\ldots$ & $\ldots$ & $\ldots$ \\
\hline $\mathrm{J}_{n}\left(\mathrm{Lat}_{n}, \mathrm{Lon}_{n}\right)$ & & & $\ldots$ & 0 \\
\hline
\end{tabular}

$$
\begin{aligned}
d_{J}^{\prime}= & \operatorname{ACOS}\left(\operatorname{COS}\left(\operatorname{RADIANS}\left(90-\operatorname{Lat}_{\alpha}\right)\right) \cdot \operatorname{COS}\left(\operatorname{RADIANS}\left(90-\operatorname{Lat}_{\beta}\right)\right)+\operatorname{SIN}\left(\operatorname{RADIANS}\left(90-\operatorname{Lat}_{\alpha}\right)\right) \cdot\right. \\
& \left.\operatorname{SIN}\left(\operatorname{RADIANS}\left(90-\operatorname{Lat}_{\beta}\right)\right) \cdot \operatorname{COS}\left(\operatorname{RADIANS}\left(\operatorname{Lon}_{\beta}-\operatorname{Lon}_{\alpha}\right)\right)\right) * 6371
\end{aligned}
$$

Herein: $d$ - the Euclidean distance in kilometres, $J$ - city, $\alpha, \beta$ - location points, $n$ - number of demand points.

Following results, the minimum distance threshold value is revised, and sub-clusters are formed accordingly. Finally, the clustering-based two-stage transport system is constructed (Fig. 3).

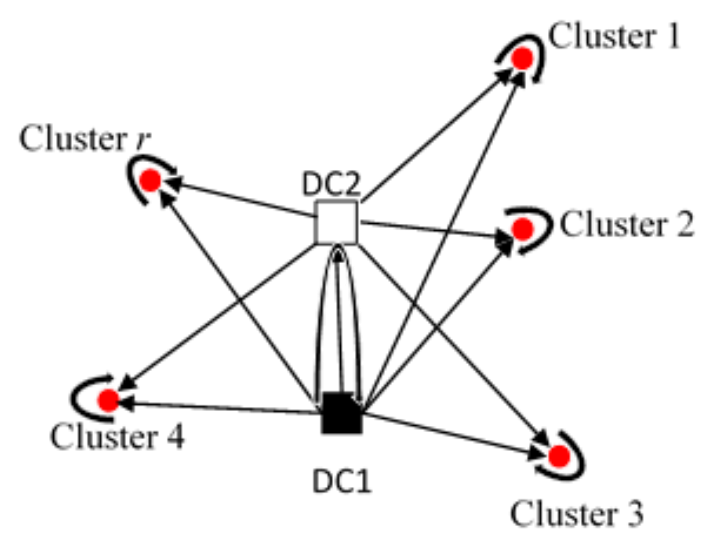

Figure 3: The structure of clustering-based two-stage transport system.

The number of clusters depends on the number of demand points and the distances among them. Demand points generate orders for transportation and all products are transported the same direction, i.e. to Cluster stores.

\subsection{Costs metrics in the transport system}

For the comparison of transport solutions, costs could be analysed on various levels. The estimation of transportation costs could be delivered by using such Eq. (4):

$$
T=w \sum_{r=1}^{t} k_{r} d_{r}
$$

herein: $T$ - transportation costs, $t$ - total number of clusters, $k$-average volume in transport units (pallets), $w$ - costs per transport unit (pallet) per kilometre, $d$-the distance in kilometres.

There are two main equations used for transportation and transshipment, presented under Eq. (5), where inputs and decision variables are used to form Eq. (5):

$p$ - supply of pallet unit from DC (pallets) $\forall \in p$

$k_{r}$-demand for pallet unit in Cluster $r$ (pallets) $\forall_{r} \in k$

$U_{r}$ - total costs for sending pallet unit from DC to Cluster $r$ (Eur/pallet) $\forall_{r}$

$x_{r}$ - flow from DC to Cluster $r$ (in pallet units) $\forall_{r}$

$q$ - minimum costs, Eur

$$
q=\operatorname{Min}\left(\sum_{r} U_{r} x_{r}\right)
$$

where three constraints must be followed by Eq. (5):

$$
\sum_{r} x_{r} \leq p, \quad \forall \in p ; \quad \sum x_{r} \leq k_{r}, \quad \forall r \in k ; \quad x_{r} \geq 0, \quad \forall_{r} .
$$


In the case of transhipment, extra constrain added to Eq. (5) for transhipment (near-by) DCs:

$$
\sum_{s} x_{s r}-\sum_{r} x_{r s}=0, \quad \forall_{r} \notin p, \notin k
$$

Costs specified in transportation and transshipment models could also include other operational costs which are defined on separate warehouse level.

Further on, the framework of costs elements is constructed to improve efficiency in the twostage transport system.

\subsection{The framework for modelling costs in the two-stage transport system}

The main objective is the efficiency increase in the two-stage transportation system. The main inputs for such a framework are costs constraints, which, by nature, are variable (Fig. 4). Herein, it is assumed that there are no capacity restrictions for DCs and trucks.

For the construction of the equation, the framework of costs elements and notations for those elements are provided. Below is the constructed framework for modelling costs (Fig. 4).

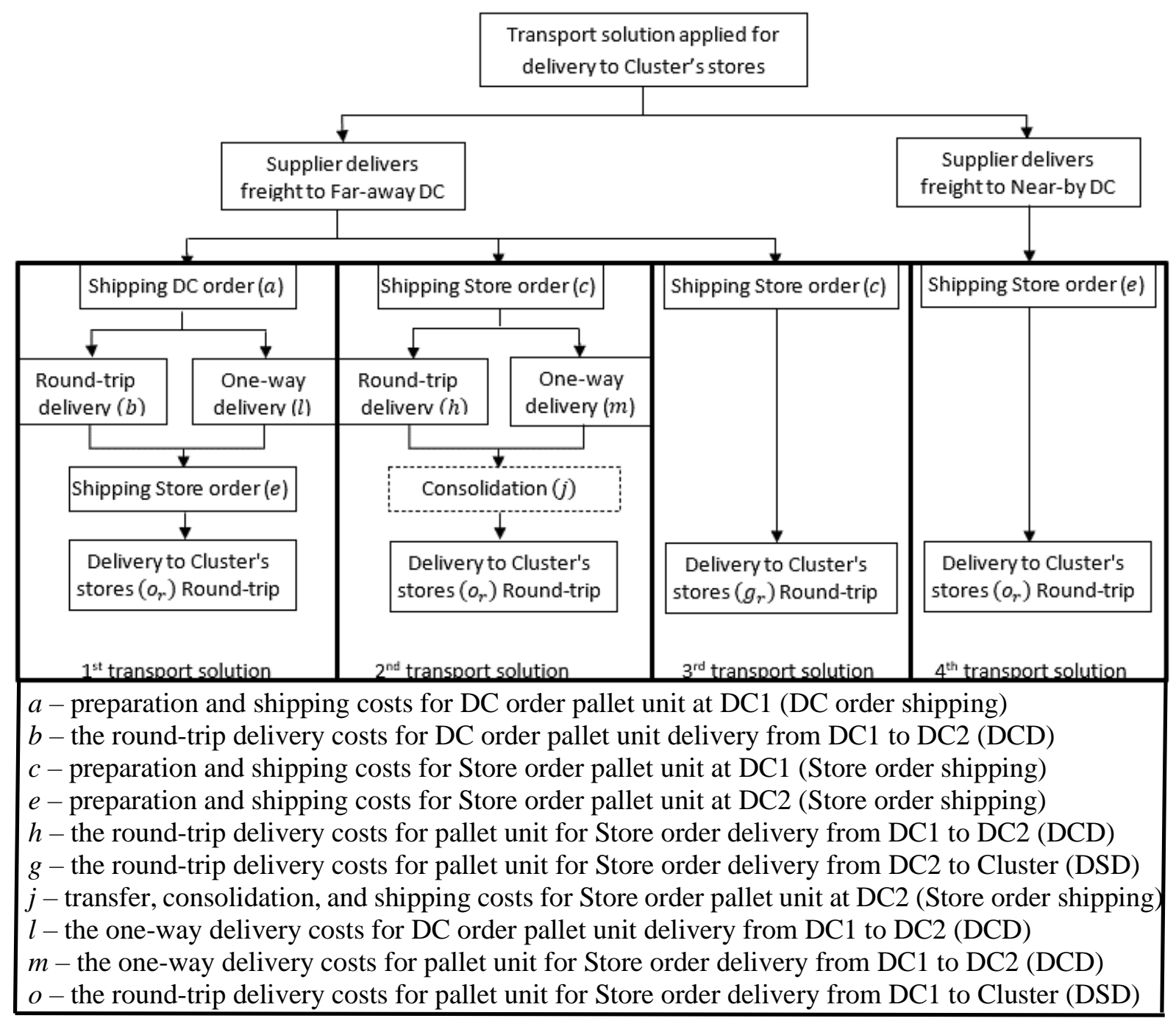

Figure 4: The framework for modelling costs in the two-stage transport system.

In Fig. 4, four transport solutions are presented. First two are quite complex. The first transport solution combines DC order and Store order shipping strategies, also DCD and DSD strategies. The second one combines Store order and Consolidation shipping strategies and integrates transshipment and DSD strategies. The third and fourth transport scenarios combine only Store order shipping and DSD strategies. 
Under first three transport solutions, suppliers deliver freights to Far-away DC (DC1), and under the fourth one - to Near-by DC (DC2). The first and second transport solution also have two alternatives - several delivery types (round-trip and one-way deliveries). The size of the costs depends on the delivery type: round-trip and one-way deliveries. Usually, one-way delivery costs are $70 \%$ lower than the delivery costs of round-trip delivery.

Based on the presented framework, the estimation of total costs for products delivery to Cluster stores in the two-stage transport system is provided. Hereon, all costs are converted to a common pallet unit by using the conversion index, which proves that the same number of cartons is supplied to demand point according to any delivery type. The conversion index from Store order to DC order in pallet units is 1.25. Following this logic, the Eq. (6) is provided for the framework specified under Fig. 4 by using the notations provided above:

$$
U_{y r}=\left\{\begin{array}{c|c}
(a+b)+\left(e+o_{r}\right) * 1.25 \\
(a+l)+\left(e+o_{r}\right) * 1.25 \\
(c+h) * 1.25+\left(j+o_{r}\right) * 1.25 \\
(c+m) * 1.25+\left(j+o_{r}\right) * 1.25 \\
\left(c+g_{r}\right) * 1.25 \\
\left(e+o_{r}\right) * 1.25 & I F \text { transport solution 1 } \\
I F \text { transport solution } 1 \gamma \\
I F \text { transport solution 2 } \\
I F \text { transport solution } 2 \gamma \\
I F \text { transport solution } 4
\end{array}\right.
$$

herein: $U$ - total costs per pallet unit, $y$ - the number of transport solution, $\gamma-$ an alternative of transport solution (specifying one-way delivery type), $r$ - unique number of the cluster.

To compare the application of all transport solutions in the two-stage transport system, the author forms a single matrix of decision variables $\left(U_{y} r\right)$ for all clusters, Eq. (7):

$$
\left[\begin{array}{ccccc}
U_{11} & U_{12} & U_{13} & U_{14} & U_{15} \\
U_{1 \gamma 1} & U_{1 \gamma 2} & U_{1 \gamma 3} & U_{1 \gamma 4} & U_{1 \gamma 5} \\
U_{21} & U_{22} & U_{23} & U_{24} & U_{25} \\
U_{2 \gamma 1} & U_{2 \gamma 2} & U_{2 \gamma 3} & U_{2 \gamma 4} & U_{2 \gamma 5} \\
U_{31} & U_{32} & U_{33} & U_{34} & U_{35} \\
U_{41} & U_{42} & U_{43} & U_{44} & U_{45}
\end{array}\right]
$$

In Eq. (7) the author focuses on the minimisation of total costs in the transport system. The efficiency increase is costs oriented and involves such dimensions as total costs per pallet unit $U$, transport solution $y$, and cluster $r$ (Fig. 5).

Transport solution $y$

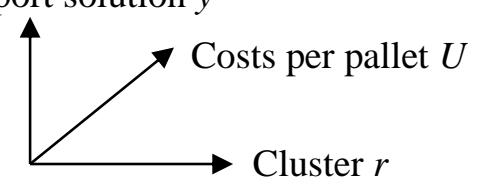

Figure 5: Efficiency evaluation directions.

All these directions are very interlinked, especially if costs structure changes. The change of expenses, for example, an increase or decrease in fuel prices, means that the revision must be performed to keep the efficiency in the transport system. Such exercise helps to find the best way for the volume supply from DCs to separate clusters.

Practical application of the proposed framework is provided below.

\section{CASE STUDY}

The case study includes two warehouses, located in different countries, and 35 demand points, which are clustered into five clusters by applying minimum distance threshold value. At first, all demand points are grouped and afterwards, the practical application of the constructed framework is delivered. 


\subsection{Clustering of demand points}

For the costs comparison, the demand points are assigned into clusters. Each Store is attached to the city by location place. Later on, cities are set to clusters, which have mid-points as defined in Table IV. Also, data diagnostics for clustering is specified accordingly: the threshold value is $85 \mathrm{~km}$; within-cluster min variation of distances - $34 \mathrm{~km}$; and within-cluster max variety of distances $-52 \mathrm{~km}$. In case, mid-points are closer than the specified threshold value; the higher hierarchical group is formed. For example, Cluster1 is created by combining two sub-clusters with mid-points placed in 43 km (Ogre, Lat 56.87 Lon 24.17; Platuone, Lat 56.56 Lon 23.73).

Table IV: The attributes of clusters and distances in kilometres.

\begin{tabular}{|l|l|c|c|c|c|c|c|c|}
\cline { 2 - 9 } \multicolumn{1}{c|}{} & Mid-point & Lat & Lon & Cluster1 & Cluster2 & Cluster3 & Cluster4 & Cluster5 \\
\hline Cluster1 & Marupe & 56.8 & 24.1 & 0 & 186 & 135 & 98 & 89 \\
\hline Cluster2 & Litene & 57.2 & 27.0 & 186 & 0 & 317 & 109 & 123 \\
\hline Cluster3 & Vanga & 56.8 & 21.8 & 135 & 317 & 0 & 233 & 202 \\
\hline Cluster4 & Pliavinios & 56.6 & 25.6 & 98 & 109 & 233 & 0 & 97 \\
\hline Cluster5 & Rozula & 57.4 & 25.0 & 89 & 123 & 202 & 97 & 0 \\
\hline DC2 (LV) & Riga & 56.9 & 24.1 & 16 & 177 & 141 & 99 & 74 \\
\hline DC1 (LT) & Vilnius & 54.6 & 25.2 & 246 & 299 & 320 & 213 & 302 \\
\hline
\end{tabular}

The cluster has a different number of cities. On the minimum, there are two cities per cluster, and on maximum - thirteen ones. Nevertheless, the number of cities is different per cluster, the demand equally distributed among clusters. The intersection of Euclidean distance lines represents midpoint - the geographical point defined by Lat and Lon values. DSD strategy from DC1 could be allocated directly to Cluster1 stores as its mid-point is $16 \mathrm{~km}$ away from DC2.

\subsection{The application of the constructed framework}

Third-party logistics providers operate in both DCs and provide costs per pallet in their contracts (Table V).

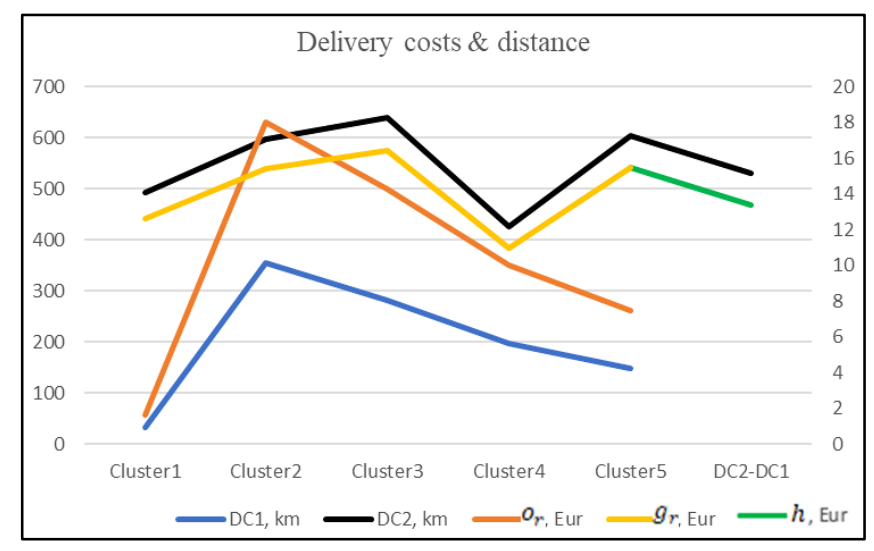

Figure 6: The link between delivery costs and distances.

Herein, delivery costs depend on labour and fuel prices, country-based regulations, and distances (presented in Fig. 6). The curves in Fig. 6 proves that round-trip delivery expenses per Store pallet unit directly depends on the distances from shipping DC and are variable ones.

Also, shipping costs depend on labour price, and shipping strategy. In case of Store order shipping, which is more labour-intensive strategy than DC order shipping, costs are $8 \%$ higher.

The author applies the framework (Fig. 4) for the case study and investigates transport solutions. Herein variables for Eq. (6) and the results of Eq. (6) application are presented in 
Table V. The first and second transport solutions have two alternatives: round-trip and one-way deliveries.

Table V: Estimation of total costs in the two-stage transport system.

\begin{tabular}{|c|c|c|c|c|c|}
\hline Variables & Cluster1 & Cluster2 & Cluster3 & Cluster4 & Cluster5 \\
\hline$a, \mathrm{c}, e, j$ (Eur) & \multicolumn{5}{|c|}{$a=5.30 ; c=5.72 ; e=10.41 ; j=3.70$} \\
\hline$b, h, l, m$ (Eur) & \multicolumn{5}{|c|}{$b=10.72 ; h=13.41 ; l=7.82 ; m=9.77$} \\
\hline$g_{r}$ (Eur) & 12.6 & 15.4 & 16.4 & 11.0 & 15.5 \\
\hline$o_{r}$ (Eur) & 1.6 & 18.0 & 14.3 & 10.0 & 7.5 \\
\hline Results & \begin{tabular}{l|l|}
$y$ & $y_{\gamma}$ \\
\end{tabular} & \begin{tabular}{l|l|}
$y$ & $y_{\gamma}$ \\
\end{tabular} & \begin{tabular}{l|l|}
$y$ & $y_{\gamma}$ \\
\end{tabular} & \begin{tabular}{l|l|}
$y$ & $y_{\gamma}$ \\
\end{tabular} & \begin{tabular}{|l|l|}
$y$ & $y_{\gamma}$ \\
\end{tabular} \\
\hline$U_{1 r} / U_{1 \gamma r}$ (Eur) & $31.0 / 28.1$ & $51.5 / 48.6$ & $46.9 / 44.0$ & $41.5 / 38.6$ & $38.4 / 35.5$ \\
\hline$U_{2 r} / U_{2 \gamma r}$ (Eur) & $30.5 / 25.9$ & $51.0 / 46.5$ & $46.4 / 41.9$ & $41.03 / 36.5$ & $37.9 / 33.4$ \\
\hline$U_{3 r}$ (Eur) & 24.5 & 28.0 & 29.3 & 22.5 & 28.2 \\
\hline$U_{4 r}$ (Eur) & 15.0 & 35.5 & 30.9 & 25.5 & 22.4 \\
\hline$U_{1 r} / U_{1 \gamma r}$ vs $U_{1 r}(\%)$ & $0 \% / 9 \%$ & $0 \% / 6 \%$ & $0 \% / 6 \%$ & $0 \% / 7 \%$ & $0 \% / 8 \%$ \\
\hline$U_{2 r} / U_{2 \gamma r}$ vs $U_{1 r}(\%)$ & $2 \% / 16 \%$ & $10 \% / 10 \%$ & $11 \% / 11 \%$ & $12 \% / 12 \%$ & $13 \% / 13 \%$ \\
\hline$U_{3 r}$ vs $U_{1 r}(\%)$ & $26 \%$ & $49 \%$ & $41 \%$ & $50 \%$ & $31 \%$ \\
\hline$U_{4 r}$ vs $U_{1 r}(\%)$ & $52 \%$ & $31 \%$ & $34 \%$ & $39 \%$ & $42 \%$ \\
\hline
\end{tabular}

Results presented in Table $\mathrm{V}$ show that the first transport solution is not economically attractive, and the most attractive ones are the third and the fourth transport solutions. Results depend on the combination of shipping and delivery costs. The costs for each transport solution are benchmarked with the costs for the first transport solution (following results of Table $\mathrm{V}$ and the application of convergence method) and are specified per Cluster $\left(U_{1 r}\right)$ :

- The costs for Cluster 1 are minimised by $52 \%$, in case the $4^{\text {th }}$ transport solution is applied,

- The costs for Cluster 2 - by $49 \%$, in case the $3^{\text {rd }}$ transport solution is applied,

- The costs for Cluster 3 - by $41 \%$, in case the $3^{\text {rd }}$ transport solution is applied,

- The costs for Cluster 4 - by $50 \%$, in case the $3^{\text {rd }}$ transport solution is applied,

- The costs for Cluster5 - by $42 \%$ in case the $4^{\text {th }}$ transport solution is applied.

The mathematical average of above-presented values gives the reduction of $47 \%$ in costs. By entering these costs to the Eq. (7), the author prepares the 3D plot diagram (Fig. 7).

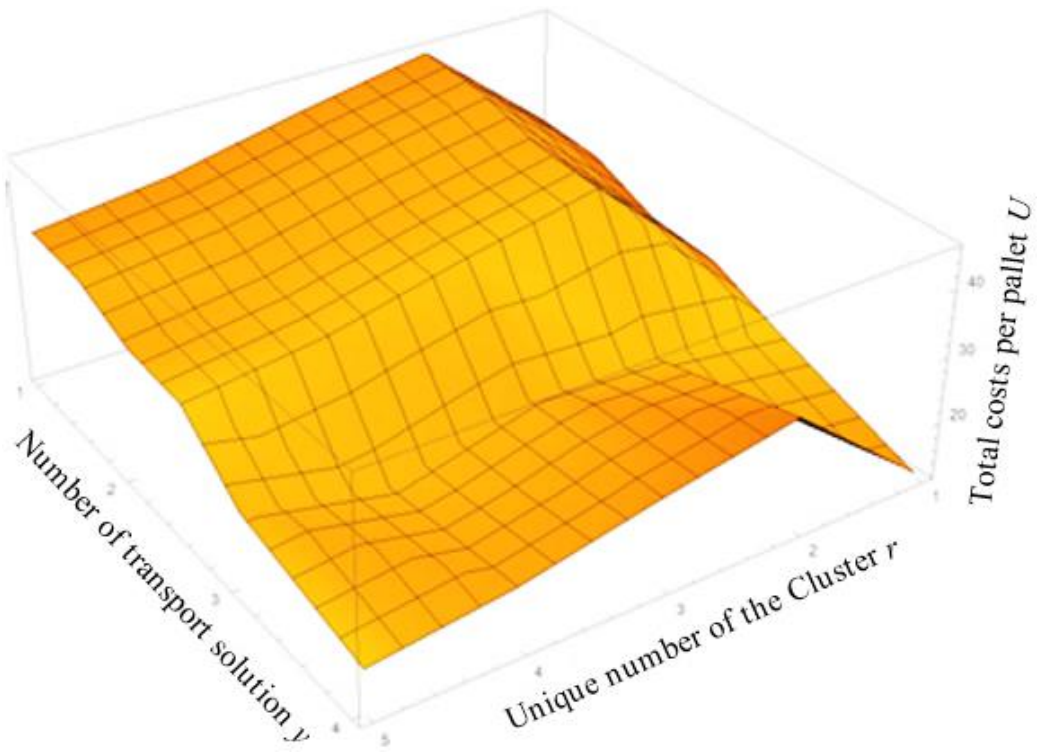

Figure 7: The application results of the framework for costs modelling in a two-stage transport system. 
For higher efficiency, the most economically attractive transport solution should be selected. For efficiency increase, the combined implementation of Store order shipping and DSD delivery strategies is important. Nevertheless, the most economical supply is reached under the third and the fourth transport solutions.

The performed practical assessment shows that the constructed framework is applicable for efficiency evaluation in the two-stage transport system. As the framework is a single period, its application for future periods is highly suggested.

\section{CONCLUSION}

The paper investigates efficiency improvement in the two-stage transport system. The twostage transport system is quite complex, and for its efficient setup, many strategies could be selected. The review of the literature shows that various strategies are investigated under different problem families. However, these strategies are usually not combined for reaching higher efficiency.

So, in this paper, the author combines shipping and delivery strategies into transport solutions and investigates the opportunity for efficiency increase. The author develops the framework for modelling costs in the two-stage transport system and presents its practical application. The demand points are clustered following minimum distance threshold value. During the framework application, the costs for constructed transport solutions are examined for each cluster. By reviewing various combinations, the author identified that the combination of store order shipping and direct store delivery strategies is giving the best results. The application of the framework helps to identify which transport solution makes the transport system more efficient. On average, around $47 \%$ of costs could be saved, when the third and the fourth transport solutions are implemented. According to these results, store order delivery to demand points located in the first and the fifth clusters is suggested from near-by warehouse and to other clusters - from the far-away warehouse.

The costs elements in the developed framework are single period. So, the constant review of costs changes over-time is required to maintain efficiency in the two-stage transport system in future.

The research has some limitations, and this study could be extended to several directions:

- review of various products-oriented strategies;

- analysis of delivery lead-time in the two-stage transport system;

- revision of three-stage transport system.

Further on, other directions could be involved in the setup of the efficient transport system.

\section{ACKNOWLEDGEMENT}

This project has received funding from European Regional Development Fund (project No 01.2.2-LMTK-718-03-0030) under grant agreement with the Research Council of Lithuania (LMTLT).

\section{REFERENCES}

[1] Ambrosino, D.; Scutella, M. G. (2005). Distribution network design: New problems and related models, European Journal of Operational Research, Vol. 165, No. 3, 610-624, doi:10.1016/ j.ejor.2003.04.009

[2] Gendron, B.; Semet, F. (2009). Formulations and relaxations for a multi-echelon capacitated location-distribution problem, Computers \& Operations Research, Vol. 36, No. 5, 1335-1355, doi:10.1016/j.cor.2008.02.009

[3] Lin, J.-R.; Lei, H.-C. (2009). Distribution systems design with two-level routing considerations, Annals of Operations Research, Vol. 172, No. 1, Paper 329, doi:10.1007/s10479-009-0628-y 
[4] Nguyen, V.-P.; Prins, C.; Prodhon, C. (2012). A multi-start iterated local search with tabu list and path relinking for the two-echelon location-routing problem, Engineering Applications of Artificial Intelligence, Vol. 25, No. 1, 56-71, doi:10.1016/j.engappai.2011.09.012

[5] Shaabani, H.; Kamalabadi, I. N. (2016). An efficient population-based simulated annealing algorithm for the multi-product multi-retailer perishable inventory routing problem, Computers \& Industrial Engineering, Vol. 99, 189-201, doi:10.1016/j.cie.2016.07.022

[6] De, A.; Mogale, D. G.; Zhang, M.; Pratap, S.; Kumar, S. K.; Huang, G. Q. (2020). Multi-period multi-echelon inventory transportation problem considering stakeholders behavioural tendencies, International Journal of Production Economics, Vol. 225, Paper 107566, 49 pages, doi:10.1016/ j.ijpe.2019.107566

[7] Lin, J.-R.; Nozick, L. K.; Turnquist, M. A. (2006). Strategic design of distribution systems with economies of scale in transportation, Annals of Operations Research, Vol. 144, No. 1, 161-180, doi:10.1007/s10479-006-0004-0

[8] Wang, Y.; Zhang, S.; Assogba, K.; Fan, J.; Xu, M.; Wang, Y. (2018). Economic and environmental evaluations in the two-echelon collaborative multiple centers vehicle routing optimisation, Journal of Cleaner Production, Vol. 197, Part 1, 443-461, doi:10.1016/j.jclepro.2018.06.208

[9] Nakhjirkan, S.; Mokhatab Rafiei, F. (2017). An integrated multi-echelon supply chain network design considering stochastic demand: A genetic algorithm based solution, Promet - Traffic \& Transportation, Vol. 29, No. 4, 391-400, doi:10.7307/ptt.v29i4.2193

[10] Cuda, R.; Guastaroba, G.; Speranza, M. G. (2015). A survey on two-echelon routing problems, Computers \& Operations Research, Vol. 55, 185-199, doi:10.1016/j.cor.2014.06.008

[11] Marianov, V.; Eiselt, H. A. (2016). On agglomeration in competitive location models, Annals of Operations Research, Vol. 246, No. 1-2, 31-55, doi:10.1007/s10479-014-1704-5

[12] Gonzalez-Feliu, J. (2011). Two-echelon freight transport optimisation: unifying concepts via a systematic review, WPOM - Working Papers on Operations Management, Vol. 2, No. 1, 18-30

[13] Mirzapour Al-e-hashem, S. M. J.; Rekik, Y. (2014). Multi-product multi-period inventory routing problem with a transshipment option: A green approach, International Journal of Production Economics, Vol. 157, 80-88, doi:10.1016/j.ijpe.2013.09.005

[14] Balamurugan, T.; Karunamoorthy, L.; Arunkumar, N.; Santhosh, D. (2018). Optimisation of inventory routing problem to minimise carbon dioxide emission, International Journal of Simulation Modelling, Vol. 17, No. 1, 42-54, doi:10.2507/IJSIMM17(1)410

[15] Drezner, T.; Drezner, Z.; Schöbel, A. (2018). The Weber obnoxious facility location model: A Big arc Small arc approach, Computers \& Operations Research, Vol. 98, 240-250, doi:10.1016/j.cor.2018.06.006

[16] Aboolian, R.; Berman, O.; Krass, D. (2021). Optimising facility location and design, European Journal of Operational Research, Vol. 289, No. 1, 31-43, doi:10.1016/j.ejor.2020.06.044

[17] Kedia, A.; Kusumastuti, D.; Nicholson, A. (2019). Establishing collection and delivery points to encourage the use of active transport: A case study in New Zealand using a consumer-centric approach, Sustainability, Vol. 11, No. 22, Paper 6255, 23 pages, doi:10.3390/su11226255

[18] Oršič, J.; Rosi, B.; Jereb, B. (2019). Measuring sustainable performance among logistic service providers in supply chains, Technical Gazette, Vol. 26, No. 5, 1478-1485, doi:10.17559/TV20180607112607

[19] Daskin, M. S.; Tucker, E. L. (2018). The trade-off between the median and range of assigned demand in facility location models, International Journal of Production Research, Vol. 56, No. 12, 97-119, doi:10.1080/00207543.2017.1401751

[20] Dupljanin, D.; Mirkovic, M.; Dumnic, S.; Culibrk, D.; Milisavljevic, S.; Sarac, D. (2019). Urban crowdsourced last mile delivery: mode of transport effects on fleet performance, International Journal of Simulation Modelling, Vol. 18, No. 3, 441-452, doi:10.2507/IJSIMM18(3)481 